Paul R. Howell FrCa,* David R. Gambling FrCPC, $\dagger$

Timothy Pavy FanzCA FRCA, $\ddagger$

Graham McMorland FRCPC,

M. Joanne Douglas FRCPC

\section{Patient-controlled analgesia following Caesarean section under general anaesthesia: a comparison of fentanyl with morphine}

in VAS scores for pain and patient satisfaction, or for side effects (nausea, itch, and sleepiness) between fentanyl or morphine. However; more patients in the fentanyl group required supplementary boluses or alterations to the PCA settings $(13 / 18$ vs 4/19:P = 0.005), and one patient was removed from the study due to inadequate analgesia. We conclude that fentanyl is not recommended for routine PCA use following Caesarean section.

Cette étude randomisée et à double aveugle compare la PCA au fentanyl avec la PCA à la morphine pour l'analgésie postcésarienne. Après une anesthésie générale standard, 37 femmes sont réparties pour recevoir soit du fentanyl $(n=18)$ soit de la morphine $(n=19)$. La PCA est débutée à la salle de réveil dès que les patientes se sentent confortables sous une solution appropriée de morphinique (dose moyenne requise, fentanyl 375 $\mu \mathrm{g}$ ou morphine $16 \mathrm{mg}$ ). Le régime initial consiste en un bolus d'un $\mathrm{ml}$ (fentanyl $25 \mu \mathrm{g}$ ou morphine $1 \mathrm{mg}$ ), un intervalle de sécurité de dix minutes, sans perfusion continue. Les deux solutions produisent une analgésie satisfaisante pour $37 \mathrm{~h}$ en moyenne avec un degré élevé de satisfaction pour la patiente, et on ne note pas de différence entre le fentanyl et la morphine pour l'évaluation de la douleur par EVA, le degré de satisfaction, et pour les effets secondaires (nausée, prurit et somnolence). Cependant, plus de patientes sous fentanyl ont eu besoin de bolus supplémentaires ou des modifications aux réglages de la $P C A(13 / 18$ vs 4/19; $P=0,005)$. Une patiente est exclue de l'étude pour raison d'insuffisance d'analgésie. En conclusion, nous ne recommandons pas la PCA au fentanyl après la césarienne.

Caesarean section is frequently performed under regional anaesthesia, and in many units epidural or intrathecal opioids are used to provide effective postoperative analgesia. For women who receive general anaesthesia the 
standard treatment for postoperative pain is commonly based on intermittent intramuscular opioids. However, several studies have shown that this technique provides poor pain relief compared with the alternatives of epidural opioids or iv patient-controlled analgesia (PCA) ${ }^{1,2}$ Apart from superior pain control, these studies have shown greater patient satisfaction with PCA than with im opioids.

The most commonly investigated drug for PCA has been morphine, but effective analgesia is associated with a variable degree of nausea, sedation and pruritus. In their assessment of PCA morphine for Caesarean section, Harrison et al. ${ }^{2}$ postulated that an agent with a more rapid onset, less sedation and fewer adverse effects might be preferable. This study was designed to investigate whether the PCA use of fentanyl would be associated with higher levels of analgesia and satisfaction, and less side effects than morphine.

\section{Methods}

Following Ethics Committee approval 37 patients who received general anaesthesia for elective or urgent Caesarean section were entered into this double-blind, randomised study. Patients who could not communicate in English, were allergic to opioids, or who were morbidly obese or suffering cholestasis of pregnancy were excluded from the study. All patients gave informed consent and the PCA system was carefully explained to them prior to surgery. They all received a standard anaesthetic and following oral sodium citrate premedication, preoxygenation and application of cricoid pressure, a rapidsequence induction-intubation was performed using thiopentone $4 \mathrm{mg} \cdot \mathrm{kg}^{-1}$ and succinylcholine $1.5 \mathrm{mg} \cdot \mathrm{kg}^{-1}$. Maintenance of anaesthesia was with nitrous oxide, oxygen and isoflurane, and of muscle relaxation with atracurium, vecuronium or a succinylcholine infusion. Following delivery of the baby, fentanyl, $3 \mu \mathrm{g} \cdot \mathrm{kg}^{-1}$, was administered. Neuromuscular blockade was reversed at the conclusion of surgery.

In the recovery room patients were randomly assigned to receive either morphine (group M) or fentanyl (group F) iv via either an Abbott Life Care Infuser or a BARD PCA device. The analgesic solutions were prepared and PCA pumps connected by a second anaesthetist in order to maintain the double-blind nature of the study. The PCA device was programmed with the following variables: bolus $1 \mathrm{ml}$, lock-out time ten minutes, maximum dose $6 \mathrm{ml} \cdot \mathrm{hr}^{-1}$, no background infusion. Solution $\mathrm{M}$ contained morphine diluted to $1 \mathrm{mg} \cdot \mathrm{ml}^{-1}$ with saline, and solution $F$ contained fentanyl diluted to $25 \mu \mathrm{g} \cdot \mathrm{ml}^{-1}$ with saline.

Patients were then given $2 \mathrm{ml}$ increments of the study (blinded) solution (i.e., $\dot{i}$ boluses of either morphine 2
TABLE I Demographic data (mean \pm SD)

\begin{tabular}{lll}
\hline & $\begin{array}{l}\text { Morphine } \\
n=19\end{array}$ & $\begin{array}{l}\text { Fentanyl } \\
n=18\end{array}$ \\
\hline Age: $\mathrm{yr}$ & $30.0(5.0)$ & $29.6(6.1)$ \\
Height: $\mathrm{cm}$ & $162(4.6)$ & $169(5.8)$ \\
Weight: $\mathrm{kg}$ & $72.1(10.5)$ & $72.2(12.0)$ \\
Gestation: $\mathrm{wk}$ & $37.2(2.9)$ & $36.3(3.5)$ \\
Duration of PCA: $\mathrm{hr}$ & $36.9(11.4)$ & $37.3(10.7)$ \\
\hline
\end{tabular}

mg or fentanyl $50 \mu \mathrm{g}$ ) until they were considered by the anaesthetist to be comfortable with minimal pain on deep breathing. Once adequate analgesia had been achieved patients were asked to mark $100 \mathrm{~mm}$ visual analogue scales (VAS) for:

- pain at present

- worst pain over past two hours

- itching

- nausea

- sleepiness

- satisfaction with pain relief.

The PCA device was then connected directly into the $\dot{\nu}$ line (with antisiphon valve). The nursing staff were instructed that any problems with the device or patient should be referred immediately to the study anaesthetist. Patients were nursed in the routine post-delivery ward and were subject to routine respiratory observations.

Further VAS assessments were carried out at 2, 4, 8 or 16,24 and $48 \mathrm{hr}$ after connecting the PCA device. If analgesia was considered inadequate at any stage by the patient the anaesthetist was called and could give additional boluses of PCA solution, then reduce the lockout time to five minutes, and then increase the bolus size. Vomiting and spontaneous complaints of other side effects were recorded, as was the need for metoclopramide, or other drugs and analgesics. Patients were also asked how many times, if any, they had awoken at night whilst receiving PCA because of pain. The patients were encouraged to use the P.CA device for up to $48 \mathrm{hr}$ from commencement. Following discontinuation, patients were asked to give a global evaluation of the technique. Pain relief thereafter was maintained with oral analgesics.

Results were analysed using Student's $t$ test, Mann Whitney test and Chi-square analysis where appropriate, and $P<0.05$ was considered significant.

\section{Results}

Thirty-seven patients were studied, with 19 women receiving morphine (Group $M$ ) and 18 receiving fentanyl (Group F). There were no differences between the groups in terms of patient age, weight, height or gestation of pregnancy (Table I). Both groups contained one patient 


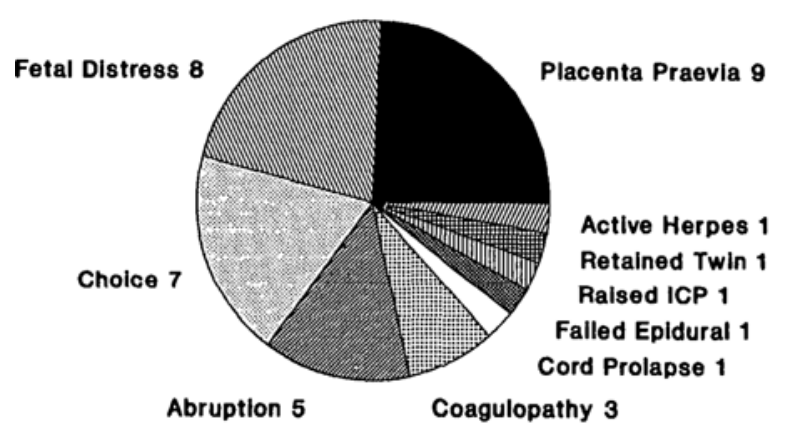

FIGURE 1 Reasons for general anaesthesia.

TABLE II PCA opiod consumption

\begin{tabular}{lll}
\hline & $\begin{array}{l}\text { Morphine } \\
n=19\end{array}$ & $\begin{array}{l}\text { Fentanyl } \\
n=18\end{array}$ \\
\hline $\begin{array}{l}\text { Mean 8-hr dose (SD) } \\
\text { (range) }\end{array}$ & $\begin{array}{l}19 \mathrm{mg}(6.6) \\
(8-30 \mathrm{mg})\end{array}$ & $\begin{array}{l}710 \mu \mathrm{g}(475) \\
(200-2275 \mu \mathrm{g})\end{array}$ \\
$\begin{array}{l}\text { Mean 24-hr dose (SD) } \\
\text { (range) }\end{array}$ & $\begin{array}{l}41 \mathrm{mg}(16.1) \\
(15-74)\end{array}$ & $\begin{array}{l}1875 \mu \mathrm{gg}(1450) \\
(650-6265)\end{array}$ \\
$\begin{array}{l}\text { Number of patients needing } \\
\text { intervention }\end{array}$ & 4 & $13^{*}$ \\
\hline
\end{tabular}

$* P=0.005$.

who was receiving magnesium sulphate by infusion for pre-eclampsia, and one patient who was a known intravenous drug abuser. The indications for performing the Caesarean sections under general anaesthesia are shown in Figure 1, and the procedure was considered to be urgent in $11 / 19$ and $11 / 18$ patients in Groups $M$ and $F$ respectively.

In the recovery room, patients required a similar mean volume of analgesic solution (Group $\mathrm{M}=16 \mathrm{ml}$, Group $\mathrm{F}=15 \mathrm{ml}$ ) to provide adequate immediate postoperative analgesia. This corresponds to a mean dose of either morphine $16 \mathrm{mg}$ or fentanyl $375 \mu \mathrm{g}$ being given before the PCA was commenced.

Table II shows drug utilisation over the first $24 \mathrm{hr}$, and the great inter-patient variability. The two patients using the lowest dose of opioid in each group $(15 \mathrm{mg}$ morphine or fentanyl $650 \mu \mathrm{g}$ over $24 \mathrm{hr}$ ) were receiving magnesium sulphate infusions as treatment for preeclampsia.

Patients in both groups used the PCA device for an average of $37 \mathrm{hr}$ (range: Group $\mathrm{M}=18-48$, Group F $=21-48$ ). During PCA use there was no difference between the two analgesic groups for median VAS patient scores for actual pain, worst pain, nausea, itch, sleepiness, and satisfaction with analgesia. Median (actual) pain and

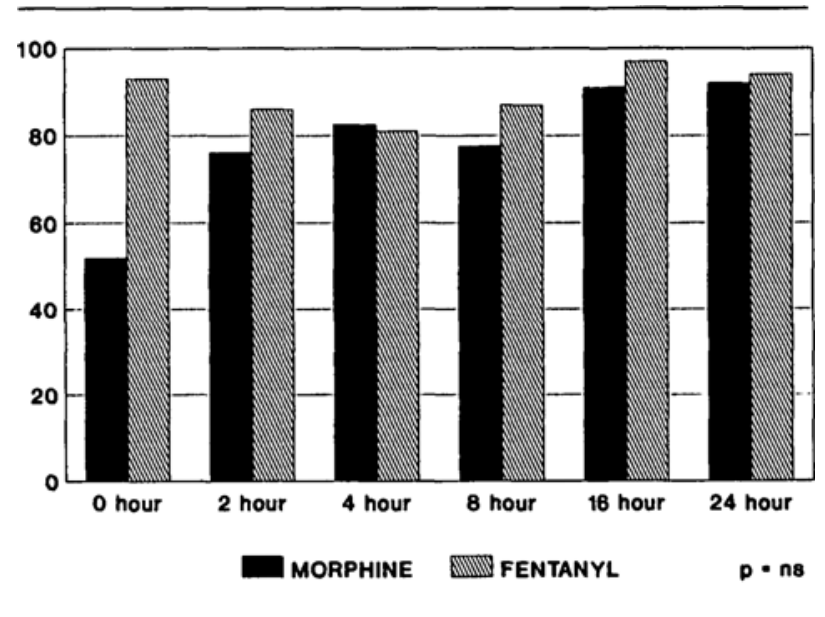

FIGURE 2 Median VAS satisfaction scores.

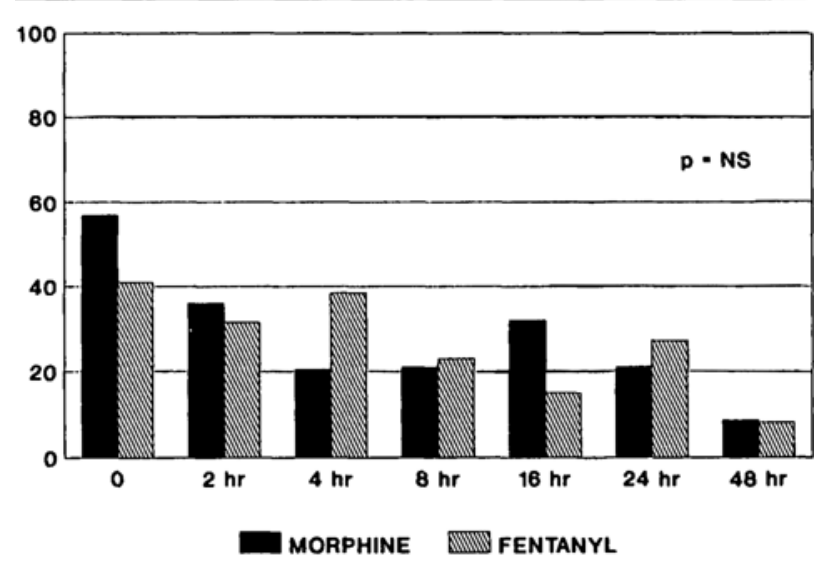

FIGURE 3 Median VAS pain scores.

satisfaction scores are shown in Figures 2 and 3. Respiratory depression, as indicated by a decrease in respiratory rate below ten breaths per minute, was not observed in any patient during the study.

More patients in Group F (13/18) required one or more supplemental boluses of analgesic solution or alterations to the PCA settings than in Group M (4/19) $(P=0.005)$. Five patients receiving fentanyl needed three or more re-adjustments, but only one in Group $M$ needed a second re-adjustment. In addition, one patient from Group F was removed from the study as she could not remain comfortable on PCA and required three supplemental doses of im meperidine.

Four patients in Group $F$ vomited once or twice in the first $24 \mathrm{hr}$ of PCA usage and two of these received an anti-emetic medication. One patient in Group M vom- 
ited once, and another received an anti-emetic for nausea. One other patient in Group $M$ required naloxone 0.2 $\mathrm{mg}$ for pruritus. Three patients in Group $\mathrm{M}$ and one in Group $F$ were given supplemental oral analgesics (Tylenol \#3 - an acetominophen/codeine/caffeine compound) after adjustments had been made to PCA settings. Six patients in Group M stated that they had awoken because of pain (an average of 4.7 times) on the first night compared with eight patients awakening in group $F$ (an average of 4.8 times). On the second night four patients in Group $M$ (out of eleven still using PCA) awoke an average of three times, compared to seven out of ten patients in Group F awakening an average of four times. These differences did not reach statistical significance.

At the end of PCA usage patients were asked a series of questions to evaluate the PCA service. The responses to the question: "If you were to tell a friend about the PCA machine, how would you rate the pain control that you received overall?" can be seen in Figure 4. All patients expressed a wish to use the PCA system again (with the exception of the patient in Group F who was removed from the study).

\section{Discussion}

This study demonstrates that both PCA morphine and PCA fentanyl provide effective pain relief following Caesarean section, with high levels of patient satisfaction and few side effects. Despite the different pharmacological profiles of the two opioids, no differences were shown in the quality of analgesia produced, or the incidence or severity of major side effects (respiratory depression, nausea and vomiting, pruritus, sedation). However, in order to maintain adequate analgesia with PCA fentanyl, over $70 \%$ of patients required several re-adjustments to the PCA settings or supplemental boluses. The PCA morphine provided more reliable analgesia, requiring little alteration or attention once established. Patients in both groups showed widely varying drug requirements, a common finding in PCA studies.

Immediately after surgery, patients required a mean of $16 \mathrm{ml}$ morphine solution $(16 \mathrm{mg})$ or $15 \mathrm{ml}$ fentanyl solution $(375 \mu \mathrm{g})$ to provide adequate analgesia. This demonstrates several things. Fisrtly, analgesia is frequently inadequate in the recovery room, and it requires a relatively large amount of opioid to control pain immediately after surgery. It must be remembered that providing an adequate level of comfort before starting PCA is essential for it to be successful. Secondly, since both drugs were given in a double-blind manner, and similar volumes were required, it seems reasonable to assume that the PCA solutions were of comparable analgesic effectiveness. However, it may be that the shorter duration

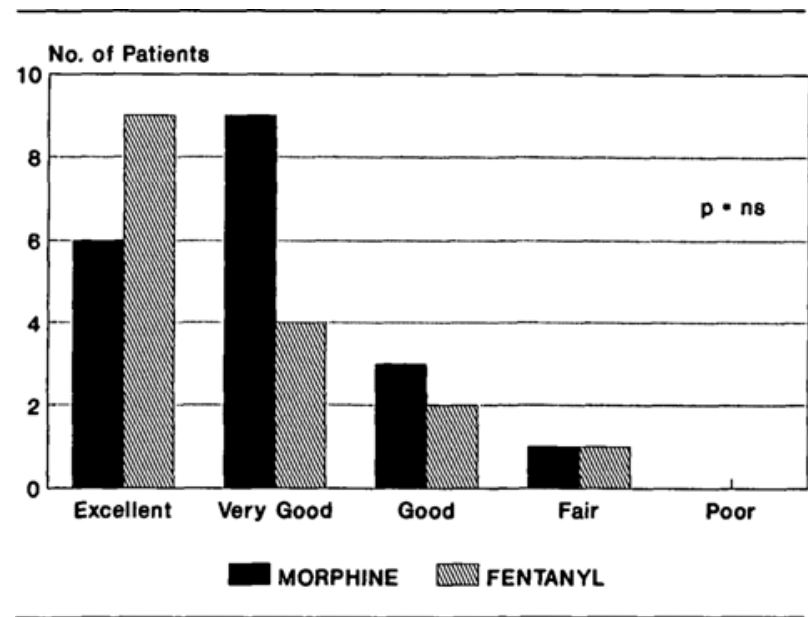

FIGURE 4 Overall patient rating.

of fentanyl necessitates a shorter lock-out time than ten minutes. Other manoeuvres that might provide more reliable analgesia with fentanyl include a larger bolus dose or a background infusion, although this may be associated with increased opioid side effects. ${ }^{3}$ Owen et al. have questioned the value of concurrent infusions during $\mathrm{PCA}^{4}$

It is interesting that the two patients who were receiving magnesium sulphate for pre-eclampsia had the lowest opioid requirement in each group. It is possible that magnesium has a synergistic effect with opioids, although this has not been previously reported. Although this apparent opioid-sparing effect may be coincidental it may be worthy of further study.

Two patients (one in each group) who were known intravenous drug abusers were successfully managed by PCA, although both needed shorter lock-out times to accommodate their increased opioid requirements. By allowing patients to give their own analgesia (within preset safety limits) PCA may be the technique of choice for providing effective pain relief in opioid abusers with pain.

Morphine is an inexpensive drug compared with the synthetic opioid fentanyl. At the time of writing, the current (hospital) drug cost of providing an average patient with PCA for $24 \mathrm{hr}$ is Can\$1.64 for morphine (mean $41 \mathrm{mg}$ ) and Can\$22.50 for generic fentanyl (mean 1875 $\mu \mathrm{g}$ ), an almost 14-fold difference. The increased cost of PCA fentanyl was not associated with any obvious benefit.

At UBC Women's Hospital, like many others, the majority of patients receive a regional block for Caesarean section and postoperative analgesia is often provided with either epidural or intrathecal opioids. Some women have medical or personal reasons which lead them to receive 
a general anaesthetic, with subsequent analgesia usually being provided by intermittent, on-demand intramuscular opioid injections. However, it is generally recognised that the quality of postoperative pain relief these women receive is inferior to those receiving spinal opioids. Several studies support this observation, and, amongst others, Eisenach et al. have shown that both iv PCA and epidural morphine provide better pain relief than im opioid injections. ${ }^{1}$ The clinical and economic benefits of early PCA use are becoming increasingly recognised. ${ }^{5}$ We had no problems with the programming or running of the PCA devices, but Rowbotham has highlighted the ease with which human error can lead to inappropriate doses can be given. ${ }^{6}$ For this reason it is important that patients are regularly monitored for the level of sedation and any respiratory depression. A recent study has shown that the addition of droperidol to morphine for PCA use reduces the incidence of nausea and vomiting following abdominal hysterectomy. ${ }^{7}$ Droperidol may be a useful adjunct to PCA use with morphine following Caesarean section, although nausea and vomiting did not appear to present a serious problem in this study.

This study coincided with the establishment of a routine iv PCA service at Women's Hospital for women who had not received spinal opioids at Caesarean section. We believe PCA opioids have a clear place on the post-natal wards for such women, and are currently using PCA morphine in the way described in this study as our standard technique. In view of the additional programming and attention required, the lack of clinical benefit, and the much greater drug costs involved, we recommend the use of morphine rather than fentanyl for the treatment of post-Caesarean section pain by PCA.

\section{References}

1 Eisenach JC, Grice SC, Dewan DM. Patient-controlled analgesia following cesarean section: a comparison with epidural and intramuscular narcotics. Anesthesiology 1988; 68: 444-8.

2 Harrison DM, Sinatra R, Morgese L, Chung JH. Epidural narcotic and patient-controlled analgesia for postcesarean section pain relief. Anesthesiology 1988; 68: 454-7.

3 McCoy EP, Furness G, Wright PMC. Patient-controlled analgesia with and without background infusion. Analgesia assessed using the demand:delivery ratio. Anaesthesia 1993; 48: 256-60.

4 Owen H, Szekely SM, Plummer JL, Cushnie JM, Mather $L E$. Variables of patient-controlled analgesia 2. Concurrent infusion. Anaesthesia 1989; 44: 11-3.

5 Ready LB. Patient-controlled analgesia - does it provide more than comfort? (Editorial). Can J Anaesth 1990; 37: 719-21.
6 Rowbotham DJ. The development and safe use of patientcontrolled analgesia (Editorial). Br J Anaesth 1992; 331-2.

7 Sharma SK, Davies MW. Patient-controlled analgesia with a mixture of morphine and droperidol. $\mathrm{Br} J$ Anaesth 1993; 71: 435-6. 